\title{
Algunas Notas Críticas sobre el Tratamiento Judicial del Aborto en Argentina
}

Este comentario, junto a los documentos que analiza, está disponible en www.anuariocdh.uchile.cl

\author{
Soledad Pujó y Malena Derdoy*
}

\section{Introducción}

Diferentes hechos han instalado en los últimos años el debate sobre la despenalización del aborto en Argentina. El Ministro de Salud del gobierno actual se ha expresado públicamente a favor de no criminalizar a las mujeres que abortan ${ }^{1}$ y ha impulsado durante su gestión diferentes medidas para mejorar las prestaciones del Programa Nacional de Salud Sexual y Procreación Responsable, así como la creación de una Guía de Atención Post Aborto para los hospitales públicos, entre otras.

El año 2006 culminó, a su vez, con la aprobación del Protocolo Facultativo de la Convención sobre la Eliminación de todas las Formas de Discriminación contra la Mujer (CEDAW), que abre la vía de reclamo internacional ante su Comité de vigilancia, y con la sanción de la ley de anticoncepción quirúrgica, que hasta el momento estaba sujeta al arbitrio y convicciones morales de los médicos ${ }^{2}$.

Por su parte, diferentes tribunales del país han emitido fallos que sientan precedentes en la materia y que constituyen un importante avance respecto de interpretaciones judiciales de años anteriores. Sin embargo, como analizaremos a continuación, estos avances son menos significativos si se tiene en cuenta la legislación comparada, el contexto regional y el desarrollo normativo, jurisprudencial y doctrinario de los organismos internacionales de Derechos Humanos, fundamentalmente aquellos que se refieren específicamente a los derechos de las mujeres.

El objeto de esta reseña es reflejar sólo una parte del debate alrededor del aborto $^{3}$, planteada a partir de dos casos judiciales del año 2006. El primero de ellos decidido por la Corte Suprema de Justicia de la provincia de Buenos Aires y el segundo por la Corte Suprema de Justicia de la provincia de Mendoza ${ }^{4}$.

\footnotetext{
* Abogadas. Integrantes de Colectivo para la Diversidad (COPADI).

1 El Ministro de Salud -Ginés González García- se ha expresado públicamente en numerosas oportunidades en este sentido, motivado principalmente por cuestiones de sanidad pública vinculadas con la gran cantidad de abortos clandestinos practicados anualmente y su impacto en la vida y salud de muchas mujeres, sobre todo aquellas de escasos recursos económicos. Si bien algunos de sus dichos han registrado ciertos matices, siempre ha revelado una consistente y acentuada tendencia hacia la mayor amplitud posible en materia de despenalización del aborto.

2 La nueva ley habilita la ligadura tubaria y la vasectomía como opciones anticonceptivas, previo consentimiento informado y sin necesidad de autorización judicial, médica, de la pareja o cónyuge. Establece procedimientos gratuitos en hospitales públicos e impone su cobertura a seguros de salud públicos y privados.

3 Los fallos reseñados se centran sólo en algunos casos de aborto y no sobre la materia en general. Con esa perspectiva debe evaluarse el contenido de este artículo.

4 Suprema Corte de Justicia de la provincia de Buenos Aires, R., L. M., 31/07/2006, LLBA 2006 (agosto), 895; y Suprema Corte de la provincia de Mendoza, "Gazzoli Ana Rosa en J 32.081 Cano Sonia M. y ots. c/ sin demandado p/ ac. de amparo s/ per saltum", 22/08/2006. Buenos Aires y Mendoza son dos provincias de la República Argentina, que de acuerdo a su régimen federal posee tribunales provinciales con competencia para conocer en esta materia.
} 


\section{Antecedentes en materia de aborto en Argentina}

Argentina se encuentra entre el grupo de países en los que, como regla, el aborto se encuentra criminalizado. El Código Penal indica que el aborto es delito (con hasta 15 años de prisión) y únicamente suspende su penalización cuando se realiza con el fin de evitar un peligro para la vida o la salud de la madre (artículo 86, inciso 1) y cuando el embarazo proviene de una violación o de un atentado al pudor cometido sobre una mujer idiota o demente (artículo 86, inciso 2). Esta regulación data del año 1922.

Los supuestos de aborto no punibles previstos por el Código Penal rara vez fueron avalados por el Poder Judicial. Esta situación responde, entre otras causas, a concepciones religiosas arraigadas y a una aplicación sesgada de tratados internacionales que protegen expresamente el derecho a la vida desde la concepción ${ }^{5}$.

En líneas generales, las decisiones judiciales se han centrado fundamentalmente en proteger el "derecho a la vida" del feto. El derecho a la vida y a la salud de las mujeres, a la privacidad, a la no discriminación, a la autodeterminación reproductiva, a una vida libre de violencia y al no sometimiento a tratos crueles, inhumanos y degradantes, reconocidos por la Constitución argentina y por los Tratados Internacionales de Derechos Humanos, si bien son elementos relevantes dentro de la discusión y contrapesan las afirmaciones tradicionales, han tenido hasta el momento muy poca relevancia en la jurisprudencia nacional ${ }^{6}$.

Todo esto, pese a que los mismos organismos encargados de interpretar y velar por el cumplimiento de los instrumentos internacionales no sólo se han expedido sobre la compatibilidad de éstos con la legislación favorable a diferentes tipos de aborto, sino que también han expresado su preocupación y realizado recomendaciones al Estado argentino para que revise la normativa que regula la materia y, especialmente, para que remueva los obstáculos que existen para el acceso al aborto en aquellos casos en los que está legalmente permitido ${ }^{7}$.

Por su parte, la Corte Suprema de Justicia de la Nación sólo se expidió sobre el aborto en dos ocasiones: en el año 2001, avalando la realización de una "inducción del parto" en un caso de anencefalia (destacando expresamente que no se trataba de un aborto), y en el año 2002, prohibiendo la comercialización de la anticoncepción de emergencia -"píldora del día después"- por considerarla abortiva.

En la primera decisión, sólo una vez saldada la discusión sobre la inviabilidad del feto, la Corte introdujo tímidamente a las mujeres como personas con derechos propios dignos de ser protegidos. En la segunda, de no más de cuatro páginas, no existió una sola referencia a las consecuencias de la prohibición del fármaco en la vida y en la salud de las mujeres.

5 Ver, entre otras, causa $N^{\circ}$ 28991, 02/06/1989, que declaró la inconstitucionalidad del inc. 2 del art. 86 del Código Penal, Cámara de Apelaciones Civil, Comercial, Criminal y Correccional de Necochea, ED. 29-9-1994, 21/12/1993. Ver también, Juz. Corr. Bahía Blanca № 1, 24/11/2003, Lexis 1001313.

6 Ver Bergallo, Paola, "Equidad de Género: Experiencias y Perspectivas para su Exigibilidad Judicial", en La Aplicación de los Tratados de Derechos Humanos en el Ámbito Local, Centro de Estudios Legales y Sociales (CELS), Buenos Aires, año 2006, en prensa.

7 Comité Internacional de Derechos Humanos, "Observaciones Finales del Comité de Derechos Humanos: Argentina", U.N. Doc., CCPR/CO/70/ARG, 03/11/2000, párr. 14. Ver también Comité de Derechos Humanos de Naciones Unidas, caso Karen Llantoy vs. Perú, 17 de noviembre de 2005. 


\section{Los fallos de las Cortes provinciales: un regreso al debate de 1922}

Como mencionamos, el objetivo de este trabajo es analizar los debates planteados a partir de los casos resueltos por las Cortes Supremas de las provincias de Buenos Aires y Mendoza.

En primer lugar, estos fallos judiciales abordan la discusión alrededor de la constitucionalidad de las excepciones que el Código Penal argentino contempla, así como su compatibilidad con instrumentos internacionales tales como la Convención Americana sobre Derechos Humanos $(\mathrm{CADH})$ y la Convención sobre los Derechos del Niño (CDN). En otras palabras, si efectivamente la protección del nonato desde la concepción no admite el aborto en ningún supuesto.

Por otro lado, dichos fallos no sólo se centran en la compatibilidad de nuestras leyes penales con la Constitución y los Pactos internacionales, sino en el mismo alcance de los supuestos establecidos por el Código Penal. En términos específicos, analizan el alcance de las disposiciones de los incisos (1) y (2) del artículo 86 del Código Penal. Así, se refleja la competencia entre interpretaciones restrictivas y amplias del inciso (1) que asocian el peligro para la vida o la salud de la madre exclusivamente con el riesgo de muerte o, en otro sentido, con posiciones más integrales sobre los conceptos de "vida" y "salud", que incluyen nociones sobre autonomía, salud física y psíquica-emocional, intimidad y desarrollo de las personas. A su vez, se discuten los alcances del inciso (2), que aparentemente no deja claro si permite el aborto ante cualquier caso de violación o sólo frente a aquellos cometidos contra una mujer "idiota o demente".

Finalmente, las decisiones judiciales analizadas ponen de manifiesto la discusión en torno a la necesidad o no de obtener una orden judicial que controle la existencia de los supuestos del artículo 86 y que autorice al personal médico a realizar la intervención.

\section{i. ¿Son compatibles determinadas prácticas abortivas con la obligación de proteger a la persona por nacer?}

El caso de una mujer de 19 años con discapacidad mental y embarazada como consecuencia de una violación, Ilegó a la Corte Suprema de Buenos Aires luego de que el pedido de autorización para realizar un aborto fuera rechazado en las dos instancias anteriores. En dichas instancias, el argumento central fue fundado en la $\mathrm{CADH}$, en la CDN y en las constituciones nacional y provincial: "todo niño tiene derecho intrínseco a la vida desde la concepción".

Curiosamente sin llegar a declarar la inconstitucionalidad de la norma, estos tribunales inferiores sostuvieron que el artículo 86 del Código Penal no es compatible con la obligación de proteger la vida del nonato. Aún más, la jueza de menores de primera instancia afirmó que: "Ante actitudes que importan un lamentable retroceso en la protección de los derechos humanos, sostenemos el derecho a la vida y consecuentemente a la personalidad del nasciturus desde el momento de la concepción, invocando como ultima ratio, frente a toda situación de duda la aplicación del principio in dubio pro vida (...) teniendo en cuenta que todo acto que atente contra la vida del mismo importa un caso extremo de violencia familiar respecto del ser más indefenso, y haciendo aplicación de otro principio liminar del derecho de familia: el del superior interés del menor" (Considerando séptimo, fallo de primera instancia, Tribunal de Menores № 5 de La Plata -énfasis añadido-). Al mismo tiempo, como medida de protección en favor del nonato, obligó a la mujer embarazada y a su madre -representante legal- a concurrir mensualmente al juzgado con una constancia médica de control del embarazo, a la vez que solicitó a la Subsecretaría de Minoridad de la provincia que "arbitre los medios necesarios para proteger la salud física y psíquica" de la mujer abusada y del feto. Ambas medidas fueron luego ratificadas por el fallo de la Cámara de Apelaciones. 
Sin embargo, la Corte Suprema de Buenos Aires abordó el caso desde una diferente perspectiva. Los argumentos de cada uno de los votos que conformaron la mayoría no reflejan, por sí solos, el desarrollo y la producción normativa, jurisprudencial y doctrinaria de los organismos internacionales de Derechos Humanos, sobre todo aquellos que se refieren más específicamente a los derechos de las mujeres ${ }^{8}$. No obstante, de la conjunción de ellos puede obtenerse un mapa más completo y cierto sobre la legislación -nacional e internacional- vigente en esta materia.

Frente a la idea de conflicto entre la obligación de proteger la vida del nonato y el derecho de la mujer violada, los votos de mayoría destacaron el carácter relativo del primero y sostuvieron que el mismo ordenamiento internacional que define la obligación de proteger la vida desde la concepción también reconoce el derecho a la vida de las mujeres; a la libertad y seguridad personales; a la preservación de la salud y bienestar; al disfrute del más alto nivel posible de salud física, mental y moral; a la prohibición de la tortura, las penas o tratos crueles, inhumanos y degradantes; a la no injerencia arbitraria o ilegal en la vida privada, la familia, la honra y la reputación; a la no discriminación respecto de la atención médica; a la adopción de medidas adecuadas y no discriminatorias en el campo de las relaciones familiares; al aseguramiento de condiciones igualitarias con los hombres para decidir libre y responsablemente el número e intervalo de los hijos, y finalmente al acceso a la información, educación y medios que permitan ejercer estos derechos. Es decir, frente a casos como éste, la Corte se encargó de mostrar claramente el grado de complejidad de la discusión y los diferentes derechos que deben cotejarse, articularse y ponderarse.

A su vez, algunos votos señalaron específicamente que esta obligación de proteger la vida desde la concepción no implica necesariamente la criminalización del aborto. En definitiva, cualquiera sea la impronta que tome el debate alrededor de diferentes tipos de aborto, no existe una obligación constitucional -menos aún internacional- que obligue al Estado argentino a tipificar y establecer sanciones penales frente a ningún caso. Es decir, aun si se reconociera que existe una obligación de proteger la vida del nonato, de dicho reconocimiento no necesariamente se sigue la utilización de la herramienta punitiva.

Por su parte, frente a un caso similar, la Corte Suprema de Mendoza resolvió de igual manera e incluso haciendo suyas las argumentaciones de parte de los votos de la mayoría formada en la Corte de Buenos Aires. Asimismo, la Corte de Mendoza reforzó aún más, en el marco de la particular situación analizada, el argumento de la libertad sexual y autonomía de las mujeres: "es evidente que, frente a la colisión de intereses y bienes jurídicamente protegidos -vida humana vs. libertad sexual-autodeterminación-, en el caso de la concepción producida por violación -abuso sexual con acceso carnal-, la ley hace prevalecer al segundo sobre el primero" (Considerando octavo).

Por otro lado, introdujo un argumento que podría hacerse extensivo a casos que exceden los supuestos de aborto no punible previstos por el Código Penal. Dice el máximo tribunal mendocino: "el artículo 19 de Nuestra Constitución Nacional, al establecer que: las acciones privadas de los hombres que de ningún modo ofendan al orden y a la moral pública, ni perjudiquen a un tercero, están sólo reservadas a Dios, y exentas de la autoridad de los magistrados (...), contiene dos principios básicos y sustantivos de la democracia liberal, el de privacidad, que incluye el derecho a la intimidad, y el de legalidad, resultando, sobre todo el primero, esencial para diseñar un sistema de respeto a la autonomía y a la libertad personal y establecer una frontera democrática ante las atribuciones estatales para limitar los derechos" (Considerando noveno).

8 Cabe destacar especialmente el voto del Dr. Hitters, que se expide sobre la mayoría del plexo normativo disponible y aplicable al caso, incluyendo las resoluciones más relevantes y actuales del Comité de Derechos Humanos, del Comité de la CEDAW, de la Comisión Interamericana de Derechos Humanos e incluso del Tribunal Constitucional de Colombia. 


\section{ii. ¿Embarazo forzado o aborto frente a la violencia sexual?}

Como mencionamos, frente al caso de Buenos Aires, algunos votos de la mayoría y también de la disidencia se encargaron de incluir en el debate la discusión acerca de los alcances del inciso (2) del artículo 86. Esta discusión fue introducida por el Dictamen de la Procuradora General de la provincia, quien afirmó que permitir el aborto sólo en los casos en los que la mujer es mentalmente discapacitada y no hacerlo respecto de las mujeres que han sufrido el mismo tipo de abuso implica una discriminación que nuestro ordenamiento jurídico en la actualidad no podría tolerar, del mismo modo que no podría tolerar el aborto por el sólo hecho de que el feto presente signos de insania. En este sentido, la Procuradora afirmó que: "a la luz de los nuevos valores receptados tanto por nuestra Constitución como por los tratados internacionales, entiendo necesario reinterpretar el artículo (...) me veo inclinada a sostener que el artículo 86, inciso 2, exime de pena a cualquier mujer que desea no continuar con un embarazo producto de un ataque a su integridad sexual" (Dictamen de la Procuración de la Provincia de Buenos Aires, Apartado III.a.4., párr. sexto).

En la misma línea se expidió la Dra. Kogan en su voto: "el legislador ha resuelto, en casos como el que nos ocupa, no exigir actos heroicos a la mujer, una vez verificados los recaudos apropiados. De tal modo, no se advierte en la elección legislativa examinada la pretendida irrazonabilidad". A su vez, integró en su decisión la concepción amplia sobre el inciso (1) del artículo 86, exponiendo que "(...) es incuestionable que llevar adelante un embarazo proveniente de una violación, es susceptible de lesionar o agravar la salud psíquica de la embarazada; lo mismo sucede con el embarazo después de advertir gravísimas malformaciones en el feto (...) la ley vigente -por lo general mal interpretada- es mucho más clara que otras y evita los problemas que han planteado textos menos inteligentes..." (Voto de la Dra. Kogan, Considerandos $N^{\circ} 26$ y $N^{\circ} 16$, respectivamente) ${ }^{9}$.

En la vereda opuesta, los jueces que votaron en minoría restringieron la aplicación del artículo 86 a la vez que plantearon su inconstitucionalidad (en algunos votos, con la única excepción del riesgo de muerte para la mujer embarazada), utilizando argumentos similares a los ya señalados. Sostiene parte de la minoría: "haciéndome eco que en la opinión pública se pretende instalar que el debate tiene por eje un tema religioso debo señalar que esto no es así. Se trata de un tema de supervivencia de la especie humana. Se ha dicho que salvar una vida significa salvar a toda la humanidad. Para que no se me argumente que la frase ha sido tomada literalmente de la película: "La Lista de Schindler", fui a la fuente original: el Mishnah Sanhedrin capítulo IV:5 en donde se dice que todo aquel que pierde un ser pierde un mundo. Todo aquel que salva un ser salva a un mundo..." (Voto en disidencia del Dr. Domínguez, apartado III.2).

Frente a la disyuntiva de quién debe soportar las consecuencias del hecho violento que da origen al embarazo, los jueces disidentes no dudaron en señalar a la mujer. La nota más distintiva puede resumirse en las siguientes afirmaciones: "el ser engendrado a partir del acto violento no es sino otra víctima -la más indefensa e inocente- del violador (...) Si se acude al sano equilibrio que emana de la verdadera justicia, se ha de concluir que, sin dejar de entender la reacción de la madre ante el hecho punible perpetrado en persona suya, resulta jurídicamente inaceptable que el fruto de la concepción, también un ser humano, pague el delito con su vida cuando no ha sido el agresor..." (Voto en disidencia, Dr. Pettigiani, Considerando XII).

Cabe destacar también las representaciones sobre las mujeres, la maternidad y la familia que existen en las mentes de una buena parte de la judicatura. En ellas, abundan las alusiones al

\footnotetext{
9 La magistrada cita textualmente el Tratado de Derecho Penal del actual integrante de la Corte Suprema de Justicia de la Nación, Eugenio Zaffaroni. Ver Zaffaroni, Eugenio, Derecho Penal, Parte General, Ed. Ediar, Buenos Aires, 2003, p. 641 .
} 
heroísmo, a la trascendencia humanitaria del rol reproductor, a la proyección de un futuro en el que estas mujeres y sus hijos comparten escenas familiares donde reina el amor y la felicidad ${ }^{10}$. Frente a los particulares casos de aborto que reflejan los fallos analizados, la propuesta de algunos jueces para las mujeres violadas parece ser la de soportar y callar. Este pedido se realiza en el contexto de países en los que el principal obstáculo para satisfacción de sus derechos y, más especialmente, de sus libertades sexuales es la violencia -física, sexual y psíquica- ejercida en el contexto familiar ${ }^{11}$. Donde las cifras de violencia sexual ejercida contra mujeres -adultas, adolescentes y niñas- describen un paisaje aterrador que se acentúa aún más frente a la desidia institucional del Estado y la impunidad. Sin dudas, esta letra pertenece a un contrato social que ninguna mujer razonable estaría dispuesta a firmar.

\section{iii. Sobre la necesidad de contar con una orden judicial en casos de aborto no punible: ¿control en la aplicación de la ley o control de la sexualidad?}

La mayoría de la Corte Suprema de Buenos Aires expresamente dictaminó que, como ya había sostenido en fallos anteriores ${ }^{12}$, no es necesario solicitar autorización judicial para los supuestos no punibles conforme el art. 86 del Código Penal. El fallo afirma en palabras más claras: "...o lo que se pide es autorización para cumplir una conducta especialmente despenalizada, y entonces no hace falta tal autorización, porque la conducta está exenta de sanción penal; o lo que se pide es autorización para cumplir una conducta que, prima facie, coincide con un tipo penal, y entonces la autorización no puede concederse, porque un juez no puede dar venia para delinquir"13. Asimismo, en este mismo punto, el voto de la mayoría hizo expresa alusión a una recomendación, en la misma línea, realizada por el Comité de Derechos Humanos a la Argentina ${ }^{14}$.

En idéntico sentido resolvió el fallo de la Corte Suprema de Mendoza: "la aplicación del art. 86 incs. 1 y 2 del Código Penal no requiere de autorización judicial, quedando la responsabilidad de decidir si se dan los supuestos fácticos descriptos por la norma, a criterio de los médicos que, en el actual trance, atiendan a la paciente ya sea en el sector privado o en el público de la salud, aplicando los principios y reglas del buen arte de curar" (Disposición II de la parte resolutoria).

Si bien estas decisiones judiciales son alentadoras (al menos, en lo que se refiere a sus votos de mayoría), en el caso de la provincia de Buenos Aires ya existía un precedente del año 2005 que despejaba dudas y que resolvía de igual manera la discusión alrededor de este punto concreto. Dicho precedente no tuvo el peso necesario ni la fuerza para evitar la reiteración de situaciones similares. Más aún, en el transcurso de la redacción de este comentario se ha presentado un nuevo caso que reúne las mismas características de los analizados y en el cual los médicos, defensores de menores y fiscales insisten con el planteo y la solicitud de venia judicial ${ }^{15}$.

10 "Si bien es claro que tendrá marcadas dificultades para llevar adelante su rol de madre, no parece que sea incapaz de brindar afecto a su hijo y de encontrar en la maternidad un hecho motivador que le permita adquirir cierta madurez en su personalidad (...) considero que debidamente asistida podría rodearse al por nacer de un ambiente familiar idóneo" (Extracto del voto del Juez Pettigiani, Considerando XVII).

11 En el caso de Argentina, ver "Decisión prohibida: Acceso de las mujeres a los anticonceptivos y al aborto en Argentina", Human Rights Watch, 06/2005, Vol. 17, № 1 (B).

12 Corte Suprema de Justicia de la provincia de Buenos Aires, “C. P. d. P. , A. K./autorización”, 28/06/2005, Ac. 95.464.

13 Voto de disidencia del juez Domínguez, que cita una obra del constitucionalista Bidart Campos publicada en "El Derecho", T. № 114, p. 184.

14 Comité Internacional de Derechos Humanos, "Observaciones Finales del Comité de Derechos Humanos: Argentina", U.N. Doc., CCPR/CO/70/ARG, 03/11/2000, párr. 14.

15 El caso involucra a una adolescente de 14 años, embarazada tras una violación. Ver "O., M.V. s/ víctima de abuso sexual", Cámara de Apelación en lo Civil y Comercial del Departamento Judicial de Mar del Plata, 21/02/07. Si bien el caso llegó nuevamente a la Suprema Corte de la provincia de Buenos Aires, no obtuvo sentencia porque la adolescente sufrió un aborto espontáneo. 
A raíz de ello, actualmente se encuentra en discusión la necesidad de definir legalmente las pautas de actuación médica frente a estos casos. Pero el tema es otro. Las decisiones judiciales despejaron dudas respecto del alcance de las normas penales frente a situaciones específicas pero, aun así, no lograron la autoridad suficiente para determinar las acciones de los diferentes actores que se empeñan en hacer valer su visión particular por sobre las leyes y los derechos de las mujeres. El problema no es la venia judicial, sino el contenido del artículo 86. No se trata de la falta de claridad de éste sino precisamente de las soluciones jurídicas que adopta. De hecho, no existen planteos judiciales sobre la autorización para practicar un tipo de aborto no punible que no vengan acompañados de una discusión sobre la inconstitucionalidad o inaplicabilidad del contenido del artículo 86.

De todas maneras, la insistencia en la judicialización de estos casos particulares forma parte de una estrategia de obstaculización del ejercicio de los derechos legalmente reconocidos a las mujeres. La violación de las normas se perfecciona en el mismo momento en que su contenido sustantivo es vetado por el arbitrio de sus agentes de aplicación y de otros actores, ajenos a la particular situación de muchas mujeres.

El caso de Mendoza es en este punto paradigmático. Allí, la autorización judicial se requirió frente a la negativa del hospital público de realizar un aborto no punible y fue concedida por el juez de primera instancia. No obstante, el personal médico insistió en su posición original. Ya en un nuevo hospital, el aborto volvió a frustrarse a partir de la acción judicial de una asociación civil católica que cautelarmente suspendió la intervención. Así fue como la Corte de Mendoza habilitó un mecanismo poco usual Ilamado "per saltum" y fundada en razones de urgencia y gravedad institucional se abocó a intervenir en el caso antes de agotar las demás instancias.

El "recurso del paso del tiempo", inherente a la judicialización, juega un papel central en la estrategia de obstaculización del acceso al aborto en los casos permitidos por la ley. Respecto de este mismo punto, ya existía el antecedente de la Corte Suprema de Justicia de la Nación sobre anencefalia. En ese caso, cuando la autorización de la inducción del parto se hizo efectiva, la mujer demandante se encontraba en el octavo mes de embarazo y el procedimiento nunca pudo llevarse a cabo. A su vez, aquí la acción de amparo había sido presentada por la mujer a las 19 semanas de embarazo y, pese a su grave afectación psicológica, tuvo que sortear un conflicto de competencia y tres instancias antes de llegar a la Corte Suprema de la Nación para acceder a la interrupción de un embarazo intrínsecamente inviable ${ }^{16}$. Y aun así nunca pudo satisfacer su requerimiento.

Pese a las resoluciones que en este trabajo se analizan, el Poder Judicial siempre se ha caracterizado por ser implacable con las mujeres, máxime cuando están en juego los alcances de sus libertades. El carácter de víctimas o victimarias de las mujeres se diluye frente a la necesidad del escrutinio sobre sus cuerpos, sus historias y, más precisamente, sus sexualidades. Esto excede a la discusión sobre diferentes tipos de aborto y forma parte de la cosmovisión general judicial que existe frente a sus problemáticas.

Varios casos reseñados demuestran todo aquello que la judicatura está dispuesta a desplegar para ejercer este control. Sobreabundancia de pruebas, peritajes, entrevistas e indagaciones; el desfile de médicos, representantes oficiales de embriones ${ }^{17}$, jueces de primera instancia, de apelaciones

16 E. Faur y N. Gherardi, "Sexualidades y Reproducción: la perspectiva de los Derechos Humanos", en Equipo Latinoamericano de Justicia y Género (ELA), Informe sobre Género y Derechos Humanos, Ed. Biblos, p. 178.

17 Incluyendo la propuesta de que se realizara una ecografía en 3-D a los efectos de conocer "a la persona del nasciturus" y garantizar "el derecho a que el niño sea oído y atendido cualquiera sea la forma en que se manifieste". Voto en disidencia del Dr. Pettigiani, Considerando XVII. 
y tribunales superiores; cientos de páginas escritas, tiempo y recursos que se multiplican por situaciones idénticas y legalmente ya resueltas.

El caso de Buenos Aires es una muestra ostensible de esta realidad. Una madre que concurre al Poder Judicial para denunciar la violación de su hija (cuya madurez mental era equiparable a una niña de ocho años) y para solicitar la realización de un aborto legalmente contemplado, terminó en un laberinto de indagaciones propias de la inquisición: dudas sobre la existencia del abuso, alusiones a romances y experiencias sexuales previas de la víctima y sospechas sobre la acentuación de su incapacidad mental. ¿Cuál es el objeto de semejante despliegue y maltrato?

Más aún, específicamente en los dos casos provinciales comentados en este trabajo ${ }^{18}$, la realización del aborto legal incluso había sido requerida por la justicia penal para conservar la prueba y sustentar los procesos iniciados contra los abusadores. De cualquier forma, esto tampoco se tuvo en cuenta.

\section{Conclusiones}

Los fallos estudiados en esta reseña han significado, en lo formal, un avance respecto de la jurisprudencia de años anteriores. Pese a ello, no podemos perder de vista que se trata de la recreación de un debate zanjado legislativamente hace casi un siglo.

A pesar que han transcurrido más de 30 años desde que los países centrales saldaron discusiones bastante más complejas que las planteadas por estos casos, y que el nivel de desarrollo del debate internacional ha crecido marcadamente, la discusión sobre el derecho de las mujeres a decidir y disponer del propio cuerpo como condición necesaria para el ejercicio de la ciudadanía sigue siendo relegada en el ámbito jurídico local y regional.

Razonablemente, son pocos los casos que ingresan en el circuito formal del sistema judicial, pero aun así las consecuencias de la criminalización general del aborto son vastas. Si bien esta regla tiene excepciones, las decisiones judiciales muestran cómo en la práctica ella opera en forma absoluta. El efecto del Código Penal es previo a la condena y no precisamente como disuasivo.

En efecto, la criminalización absoluta del aborto no hace más que profundizar la discriminación afectando principalmente a las mujeres en situación de pobreza, que no tienen acceso a servicios privados de salud. El Comité de Derechos Humanos de la ONU se ha expresado con respecto a esta situación en Argentina, indicando su "inquietud ante los aspectos discriminatorios de las leyes y políticas vigentes, que da como resultado un recurso desproporcionado de las mujeres pobres y de las que habitan en zonas rurales a un aborto ilegal y arriesgado"19.

Son también ellas quienes sufren principalmente la violencia institucional, familiar y sexual, los abusos y los malos tratos. Sobre estas mujeres recaen los efectos de buena parte de las discusiones que este breve comentario ha relevado. Estas problemáticas se suman a otras, tales como la denegatoria de los tratamientos médicos debidos o los interrogatorios policiales que sufren muchas mujeres frente a abortos espontáneos o naturale ${ }^{20}$. Constituyen formas de castigo informal e ilegal.

18 Lo mismo sucedió en el caso "O., M.V. s/ víctima de abuso sexual", Cámara de Apelación en lo Civil y Comercial del Departamento Judicial de Mar del Plata, 21/02/07, citado en la nota № 15.

19 Comité de Derechos Humanos, "Observaciones Finales del Comité de Derechos Humanos: Argentina", U.N. Doc. CCPR/CO/70/ARG, 03/11/2000, párr. 14.

20 Ver, "Decisión prohibida. Acceso de las mujeres a los anticonceptivos y al aborto en Argentina", Human Rights Watch, op. cit., p. 63 y ss. 
El patriarcado, reforzado con las interpretaciones penales reseñadas, convierte a los médicos y al personal del servicio de salud en un andamiaje más de la estructura policial.

El mejor ejemplo de ello es que reiterados fallos de tribunales superiores los han instado a no denunciar a las mujeres que concurren a hospitales públicos con secuelas de abortos mal realizados, haciendo valer el secreto médico por sobre la obligación de los funcionarios públicos de denunciar todos los delitos que Ileguen a su conocimiento, precisamente porque está en juego la salud de las mujeres. Aun así, son numerosas las ocasiones en que los médicos y el personal hospitalario omiten cumplir estas órdenes judiciales. Incluso se han registrado casos de mujeres esposadas por las autoridades policiales a la cama del hospital hasta la desestimación de las acciones iniciadas en su contra. Este tipo de prácticas no puede estar presente en ningún debate razonable alrededor de los alcances y límites del aborto.

Lamentablemente, es en estas discusiones donde se vuelve más gráfico que, pese a los esfuerzos, la inclusión de las mujeres en la vida democrática en nuestros países sigue siendo parcial. El cuadro de situación analizado no hace más que manifestar que el sistema de control sobre sus cuerpos y autonomía, aun con leyes que expresamente favorecen sus intereses frente a situaciones específicas, sigue prácticamente intacto y reacciona de las formas más cruentas. Así, se refleja una práctica que, pese a algunas decisiones alentadoras, recuerda a las mujeres cuáles son los límites del patriarcado que no pueden franquearse. En muchos casos, esta práctica coloca a las mujeres entre la vida y la muerte, pero eso tampoco parece ser un argumento suficiente para revisarla. 